九州大学学術情報リポジトリ

Kyushu University Institutional Repository

\title{
Sensor Comparison for Grass Growth Estimation
}

\section{Kabir, Md. Shaha Nur}

Department of Biosystems Machinery Engineering, College of Agriculture and Life Sciences, Chungnam National University / Department of Agricultural and Industrial Engineering, Hajee Mohammad Danesh Science and Technology University

Chung, Sun-0k

Department of Biosystems Machinery Engineering, College of Agriculture and Life Sciences, Chungnam National University

Kim, Yong-Joo

Department of Biosystems Machinery Engineering, College of Agriculture and Life Sciences, Chungnam National University

Lee, Geung-Joo

Department of Horticultural Science, College of Agriculture and Life Sciences, Chungnam National University

他

https://doi.org/10.5109/1686491

出版情報：九州大学大学院農学研究院紀要. 61 (2)，pp.367-374，2016-09-01. Faculty of Agriculture, Kyushu University

バージョン :

権利関係 : 


\title{
Sensor Comparison for Grass Growth Estimation
}

\section{Md. Shaha Nur KABIR ${ }^{1,2}$, Sun-Ok CHUNG ${ }^{1 *}$, Yong-Joo KIM' ${ }^{1}$, Geung-Joo LEE ${ }^{3}$, Seung-Hwa YU ${ }^{4}$, Kyeong-Hwan LEE ${ }^{4}$, Takashi OKAYASU and Eiji INOUE}

\author{
Laboratory of Agricultural Machinery and Production Systems Design, Division of Bioproduction \\ Environmental Sciences, Department of Agro-environmental Sciences, Faculty of Agriculture, \\ Kyushu University, Fukuoka 812-8581, Japan \\ (Received May 2, 2016 and accepted May 10, 2016)
}

\begin{abstract}
Precision agriculture has been implemented in various cultivation operations for various crops. Recently, autonomous mower tractor with variable rate fertilization has been tried. Variable rate fertilization requires quantification of grass growth level. Objective of this study was to compare the performance of potential sensors under different growth levels and sensor operation conditions. A CCD camera, an ultrasonic module, and an optical reflectance sensor (i.e., Crop Circle) were tested at fields with different grass growth levels. Effects of sensor mounting height and angle were investigated. Effects of vehicle (i.e., mower tractor) vibration and traveling were also investigated: under static, vibration and no traveling, and vibration with traveling conditions. Results showed that sensor mounting height had a little effect on the sensor performance, and grass growth level was successfully quantified. Camera angle of $90^{\circ}$ showed the best performance with less noise. The ultrasonic sensor could work with less deviation under static condition, whereas, CCD camera proved the applicability under all operating conditions. Operation condition of the optical reflectance sensor showed a little effect on the grass growth detection results. This study would provide information useful for automated grass growth mapping and variable fertilization recommendation.
\end{abstract}

Key words: precision agriculture, grass growth, optical reflectance, ultrasonic, camera image

\section{INTRODUCTION}

Precision agriculture has been widely studied and adopted in many countries for grain and vegetable crop production, but grass or sod production has drawn relatively less interest. Cultivated turf grass is a pervasive feature of the urban landscape in many developed countries providing functional, recreational, and ornamental benefits to human activities and also contributing to the national economy (Haydu et al., 2006). Moreover, high value crops are emerging as the rice production cost increases and the aging of the rural labor force continues. The sod industry revenue is $2 \sim 3$ times of rice production with same labor input. Grasses are not only for livestock feed, but also widely applied to the stadium or the golf courses. Recent statistics showed that, due to increase in demand and diversification of grass consumers, the number of grass growing farmers increased in Korea, and grass growing area increased to 3,056 ha (17.8\%) in 2011 compared to grass production in 2006 (13.6\%) (Choi and Yang, 2006; Korea Forest Service, 2012; Youn et al., 2005; Youn et al., 2006). In Japan, sod production

\footnotetext{
${ }^{1}$ Department of Biosystems Machinery Engineering, College of Agriculture and Life Sciences, Chungnam National University, Daejeon, Republic of Korea

Department of Agricultural and Industrial Engineering, Hajee Mohammad Danesh Science and Technology University, Dinajpur, Bangladesh

${ }^{3}$ Department of Horticultural Science, College of Agriculture and Life Sciences, Chungnam National University, Daejeon, Republic of Korea

${ }^{4}$ Department of Rural \& Bio-Systems Engineering, College of Agriculture and Life Sciences, Chonnam National University, Gwangju, Republic of Korea

* Corresponding author (E-mail: sochung@cnu.ac.kr)
}

acreage was 6,623 ha in 2007, and Japan Agricultural Cooperative issued a warranty of sod production quality to the consumers for maintaining a reasonable degree of uniformity and height quality of sod production (Jang et al., 2011).

Advanced technology developments took place in turf grass-sod production to reduce labor costs efficiently. Usually, in grass management, fertilizing and mowing are the important steps to ensure the quality of the grass. In the traditional type, farmers require considerable labor and time to find less-growing parts in grass field. Efficient farming practices are needed due to increase of modern farm size and decrease of number of farmers. Advanced production management systems can promote labor saving and lower the cost of agricultural outputs (Choi et al., 2015). Research on automatic navigation of agricultural vehicles has been reported in recent years (Han et al., 2013). In Korea, most of the field operation researches have been concentrated on automation (RDA, 2013), except operations for grass production. Autonomous operation of mower tractors would provide efficient management of the mowing operation (Song et al., 2015) and obviously increase the grass quality and quantity (Kraft, 2011).

Among the sod cultivation and management practices, fertilization is one of the key issues for achieving a balance between shoot growth and root development. Excessive nitrogen promotes greater shoot growth, increases mowing costs, and makes the grass more susceptible to diseases and stress (White et al., 1991). Recently, fertirrigation technique has been developed to minimize misuse or overuse of fertilizers and to provide significant increase in production during the entire growing season (Putti et al., 2014). Therefore, optimization 
of fertilization is an important issue for the balanced growth of turf grasses in sod industries due to its environmental and economic impact.

In view of the grass growth characteristics, common methods of uniform fertilizer application can only meet normal or well growing parts, and supplementary fertilizer application for less-growing parts requires considerable labor and time. In order to standardize the grass estimation, detection of the grass growth characteristics is needed with advanced technology. Grass height and coverage density could reflect the basic grass growth characteristics. Plant height could be the reliable parameter for discriminating vegetation and soil surface. Numerous studies have been conducted to detect and discriminate between different plant communities based on their heights using ultrasonic sensors (e.g., Andújar et al., 2011; Andújar et al., 2012; Freeman et al., 2007; Shibayama et al., 1985). Therefore, we hypothesized that ultrasonic sensor could be used for less-growing area detection and discrimination between grass and soil surfaces. Standard ultrasonic sensors are the robust and relatively cheap, but their performances can be affected by the canopy structure to be detected (Escolà et al., 2011).

Another potential approach to estimate grass growth is to use optical reflectance. The normalized difference vegetation index (NDVI) is an index that can be used to differentiate plant growth across a landscape (Henik, 2012) and be related to crop variables such as biomass, leaf area, plant cover, leaf gap fraction, nitrogen and chlorophyll contents (e.g., Aparicio et al., 2000; Best and Harlan, 1985; Christensen and Goudriaan, 1993; Lukina et al., 1999). Several studies have been conducted using Crop Circle to determine the growth stages of crops. Crop Circle has provided reliable estimation of canopy development across the entire growing season (e.g., Shaver et al., 2010; Shaver et al., 2011). Camera image also can be used for grass growth estimation. If the vegetation pixels are identified, grassless area can be calculated by computer vision methods, combining the information on differences in color, position, shape, texture, and size or spectrum of the grassless areas. Performance of the camera image analysis would depend on the camera specifications, and field and grass characteristics.

Literature review showed that there have been different sensing approaches to estimate crop growth status. Performance of the methods would be affected by grass growth level, sensor mounting and operation conditions. This study was conducted to evaluate performance of different sensing methods under different grass growth levels, sensor mounting conditions (e.g., height, angle), and operation conditions (e.g., static, moving).

\section{MATERIALS AND METHODS}

\section{Sensors and field sites}

Three different sensors such as CCD camera, optical reflectance (i.e., Crop Circle) module, and ultrasonic module were tested in the study, and their major specifi-

Table 1. Specifications of the sensors used in the study

\begin{tabular}{|c|c|c|}
\hline \multirow[t]{2}{*}{ Photo } & \multicolumn{2}{|r|}{ Specifications } \\
\hline & Model and manufacturer & DFK 31BF03, Sony Co. (Japan) \\
\hline \multirow{5}{*}{ CCD camera } & Size (mm) & $50.6 \times 50.6 \times 130(\mathrm{H} \times \mathrm{W} \times \mathrm{L})$ \\
\hline & Resolution (mm) & $1280 \times 960$ \\
\hline & CCD & 1/3" Sony CCD, progressive scan \\
\hline & Camera speed (images/s) & Up to 30 \\
\hline & Interface & IEEE-1394 Digital \\
\hline \multirow{8}{*}{ Ultrasonic sensor } & Model and manufacturer & UDS10A, DAS Co. Ltd. (Korea) \\
\hline & Frequency & $40 \mathrm{kHz}$ \\
\hline & Range & $300 \sim 5,000 \mathrm{~mm}$ \\
\hline & Size & $24 \times 27 \times 51 \mathrm{~mm}(\mathrm{H} \times \mathrm{W} \times \mathrm{L})$ \\
\hline & Power supply & $15 \mathrm{VDC}$ \\
\hline & Output voltage & $0 \sim 5 \mathrm{VDC}$ \\
\hline & Weight & $25 \mathrm{~g}$ \\
\hline & Protection degree & IP65 \\
\hline \multirow{7}{*}{ Crop circle } & Model and manufacturer & ACS-430; Holland Scientific Inc., Lincoln, NE (USA) \\
\hline & Measurement channels (3) & $670 \mathrm{~nm}, 730 \mathrm{~nm}$, and $780 \mathrm{~nm}$ \\
\hline & Wide measurement range & $0.25 \mathrm{~m}$ to $2.0 \mathrm{~m}$ \\
\hline & Field-of-view & $\sim 30$ degrees by $\sim 14$ degrees \\
\hline & GPS Sample Rates & Updated at 1 and $5 \mathrm{~Hz}$ \\
\hline & Operating Temperature & $0^{\circ} \mathrm{C}$ to $50^{\circ} \mathrm{C}$ \\
\hline & Power Requirements & 9 to 17V DC@ 350mA \\
\hline
\end{tabular}


cations are summarized in Table 1. A CCD camera (model: DFK 31BF03, Sony Co., Japan) with a $1280 \times$ 960 resolution and 30 3.75 frames per second (fps) for relatively good image quality even under moving condition was used. The camera was mounted on the front of a grass mower tractor and faced down at an angle of $90^{\circ}$ to the vertical, and connected to a laptop and a LabVIEW program (ver. 2012; National Instruments; Austin, Texas, USA) was used to acquire and process the images.

For an optical reflectance sensor, a Crop Circle handheld system (model: ACS-430; Holland Scientific Inc., Lincoln, NE, USA) was selected. The model was widely used to estimate crop growth status in field conditions. NDVI (Normalized Difference Vegetation Index) usually used to indicate the vegetation coverage or crop growth status. It was hypothesized that the less-growing grass area would have lower NDVI values than better-growing areas.

Ultrasonic distance sensing module (model: UDS10A; DAS Co. Ltd., Korea) was selected to determine the grass height as an indicator of growth status. The ultrasonic sensor detection distance range was 300 6000 mm with a sampling frequency of $40 \mathrm{kHz}$. The output was interfaced with a data acquisition system (model: NI USB-

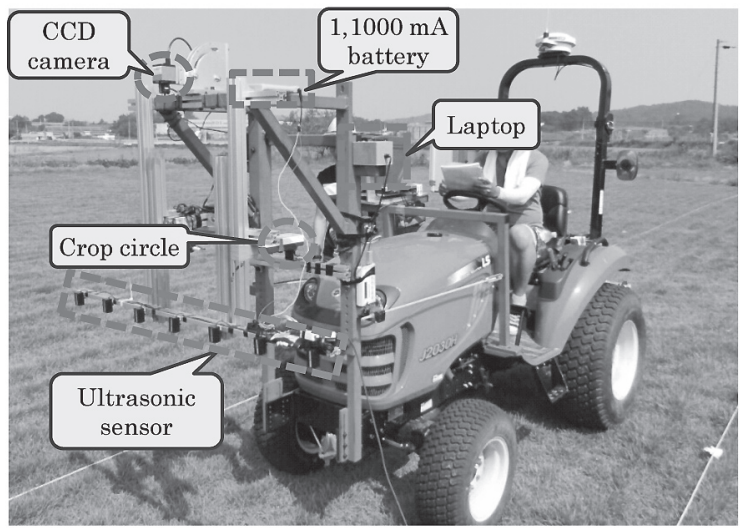

Fig. 1. Grass growth estimation system on the mower tractor.
Table 2. Soil properties of the three experimental fields

\begin{tabular}{lrrr}
\hline \multicolumn{1}{c}{ Parameter } & Field 1 & Field 2 & Field 3 \\
\hline Acreage $\left(\mathrm{m}^{2}\right)$ & 1,450 & 1,200 & 2,000 \\
Water content $(\%)$ & 31.41 & 26.94 & 20.34 \\
Soil EC (dS/m) & 0.72 & 0.69 & 0.63 \\
Soil temperature $\left({ }^{\circ} \mathrm{C}\right)$ & 27.08 & 24.28 & 31.77 \\
\hline
\end{tabular}

6009; National Instruments, Austin, Texas, USA) and connected via USB connector to a laptop. Mounting of the sensors on the grass mower tractor is shown in Fig. 1.

The tests were conducted in three fields with different overall grass growth levels, and located in Southern part of Korea (Latitude: 35.156 N, Longitude: 126.611 E). The three fields, designated as Field 1, Field 2, and Field 3 , were selected considering the coverage density of the grass about 90\%, 70\%, and 50\% reported by a skilled farmer who had an experience of grass growing over 10 years (owner of the fields). The satellite images showing the shapes of the object fields and the camera captured sample images were shown in Fig. 2. It was shown that the bare soil area increased from Field 1 to Field 3. The variety of the grass was $Z$. japonica Steud (Korean lawn). In this region of Korea, grass was usually planted from April to May and harvested from September to October about 15 months after planting. During the grass growing season in 2013, the average range of monthly temperature and rainfall was $11.4 \sim 28.4^{\circ} \mathrm{C}$ and $30.8 \sim 349.1 \mathrm{~mm}$, respectively. The experiments were performed in middle of September 2013 and the average monthly temperature was $24.5^{\circ} \mathrm{C}$. The soil properties such as water content, soil apparent electrical conductivity (EC), and soil temperature were measured by a commercial soil property sensor (model: WT1000B; Mirae Sensor, Seoul, Korea), and summarized in Table 2.

\section{Experimental and analytical procedures}

Performance of the sensors was evaluated under different operation conditions of the vehicle where the sen-

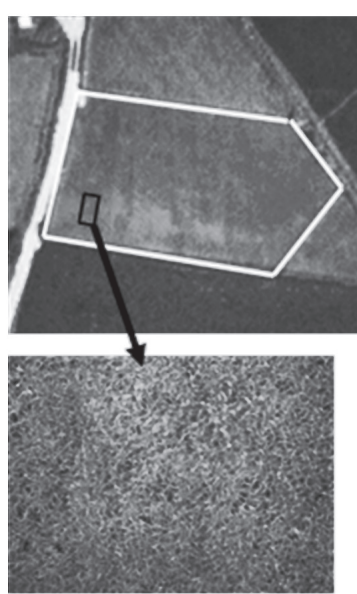

Field 1

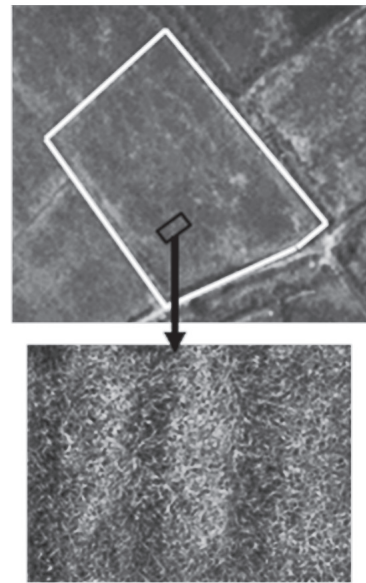

Field 2

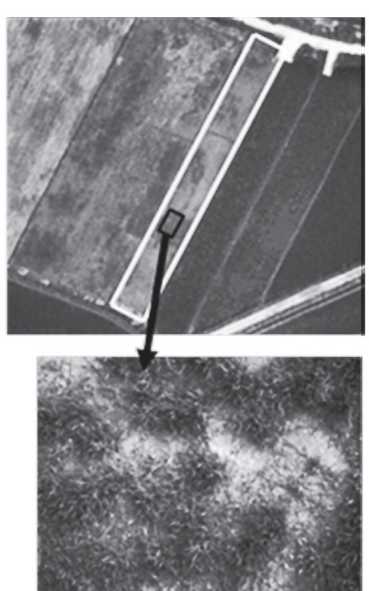

Field 3

Fig. 2. Satellite images of the experimental fields and representative sample areas. 
sors were mounted on: 1) static condition without engine start and traveling, 2) vibration condition with engine start but not traveling, and 3) traveling condition. Under the static condition, effects of camera angle and sensor mounting height were investigated. Camera angle from the horizontal line varied from $50^{\circ}$ to $90^{\circ}$ at a $10^{\circ}$ interval, and sensor mounting height varied from 60 to $100 \mathrm{~cm}$ at a $10 \mathrm{~cm}$ interval. For vibration and traveling conditions, sensor faced down vertically, and the mounting heights were $160 \mathrm{~cm}$ for the camera and $100 \mathrm{~cm}$ for the ultrasonic and Crop Circle sensors. For traveling condition, normal ground speeds for grass mowing were used (i.e., $0.45 \pm$ $0.045 \mathrm{~m} / \mathrm{s}$ ).

Fig. 3 shows a schematic diagram explaining data collection procedures from the fields. From each field, a $20 \mathrm{~m}$ long and $2 \mathrm{~m}$ wide area was selected so that grass growth levels were mostly different along the path, and divided into 20 sub-areas. Within each sub-area, measurements were obtained using the three sensors. According to the sensor characteristics, the sensor was mounted at different heights to fit the same detection width of $100 \mathrm{~cm}$. The CCD camera image captured $100 \times$ $50 \mathrm{~cm}^{2}$ area, five-ultrasonic sensor array detected twice the $100 \times 0.25 \mathrm{~cm}^{2}$ area, and Crop Circle scanned $100 \times$ $50 \mathrm{~cm}^{2}$ area. Three replicate measurements were made and averaged for each sub-area, and total 60 final measurements were obtained from the three fields. Images of the 60 sub-areas were visually investigated by the field owner and a horticultural scientist skilled in the grass management, and ranked the grass growth into 10 levels from 1 (least growing area) to 10 (most growing area). The sensor outputs were correlated to the manuallydetermined growth level.

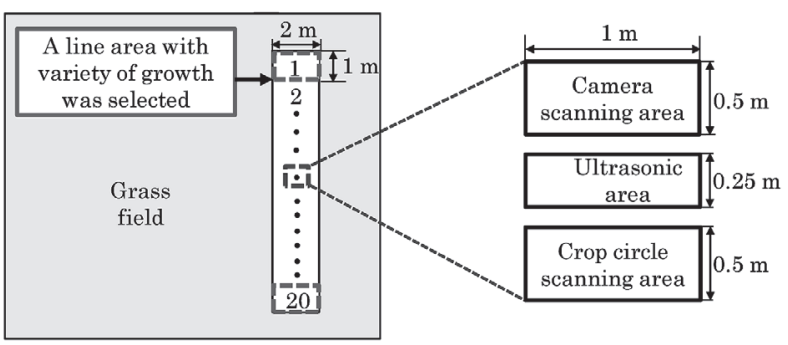

Fig. 3. Diagram explaining the data acquisition scheme.

\section{Color image segmentation (CIS)}

Image segmentation is the crucial and essential component of image analysis. An image is usually described by distribution of three color components such as red (R), green (G), and blue (B). Compared to gray scale, color image provides more information for extracting objects. The color image segmentations could be some monochrome segmentation approaches with several color spaces as described by Cheng et al. (2001). In this study, the color image segmentation (CIS) was focused on the separation of grass from the rest such as soil, stones, and others. Therefore, the CIS was based on the gray level image segmentation approach (histogram thresholding) in the RGB color space. Woebbecke et al. (1995) defined the famous agronomic contrast excess green index (ExG) index, employed for RGB images as:

$$
\begin{aligned}
& \mathrm{ExG}=2 \times \mathrm{g}-\mathrm{r}-\mathrm{b} \quad \text { with } \mathrm{r}+\mathrm{g}+\mathrm{b}=1, \\
& \mathrm{r}=\frac{R}{(\mathrm{R}+\mathrm{G}+\mathrm{B})}, \quad \mathrm{g}=\frac{G}{(\mathrm{R}+\mathrm{G}+\mathrm{B})}, \\
& \mathrm{b}=\frac{B}{(\mathrm{R}+\mathrm{G}+\mathrm{B})},
\end{aligned}
$$

where, R, G and B are the normalized RGB coordinates ranging from 0 to 1 and are obtained as:

$$
\mathrm{R}=\frac{R}{R_{\max }}, \quad \mathrm{G}=\frac{G}{G_{\max }}, \quad \mathrm{B}=\frac{B}{B_{\max }},
$$

where, $R_{\max }=G_{\max }=B_{\max }=255$ for 24-bit color images (8-bit for each band).

The images obtained from this index were binarycoded by thresholding the smoothed ExG images considering the white pixels. Gée et al. (2008) implemented an easy threshold method based on the mean gray level of the image (histogram), where the living plant material (crop or weed) appears as white spots and the rest (i.e. soil surface, stones, shadows) as black. This threshold method was applied for binarization.

The images were stored as 24-bit color pixel values with a resolution of $1280 \times 960$ and saved in RGB color space in the ".jpg" file format. The ".jpg" images were processed with the MATLAB (version R2011a, Math

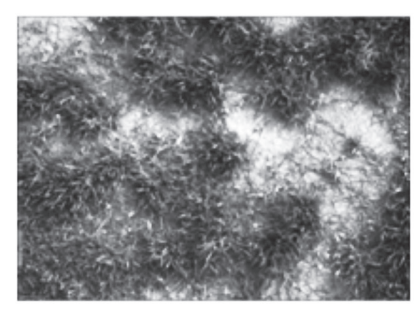

(a)

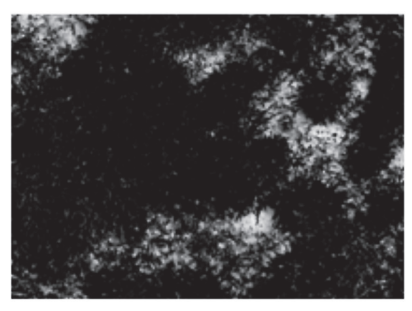

(b)

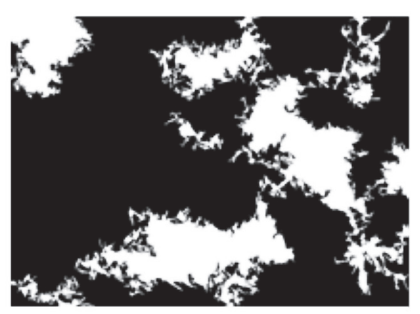

(c)

Fig. 4. Color image segmentation: (a) Original image; (b) color space transformation; (c) binary-coded image with a threshold value. 
Works, USA) to collect all of the black pixels for grass. Fig. 4 shows the total color image segmentation process such as an original image in the RGB color space of grass field, color space transformation, and finally thresholded image. The black and white represented 1 and 0 in computer calculation. Therefore, it was easier for the computer to calculate the percentage of the grassless areas. The percentage of soil was calculated from the images by taking all the 0 values in the images and expressed as CIS values indicating the grassless area for determining the grass growth level.

It was difficult to find a common threshold due to the grass characteristics of the fields. Thresholding process for camera images could not separate the grass accurately all the cases but was used to build a basic grass growth level. Some unfavorable situations such as too strong light or dead grass on the ground, some grass parts as white just like the soil often occurred in thresholding process. Therefore, thresholding for segmenting images has been adapted to solve these problems. After the CIS pre-processing, more accurate results were found for region segmentation images from the binary images. Compared to the human eye's estimation, $95 \%$ CIS process results were consistent in 60 samples.

\section{Ultrasonic sensor estimation}

Ultrasonic sensor measures the distance to the target objects based on the reflected sound waves with frequencies above human hearings range. The measured travel time from the emitter of an ultrasonic pulse to the object reflecting the pulse back to the sensor is proportional to the distance. The grass growth levels could be estimated using the height differences. The ultrasonic sensor could reflect the height of the grass as shown in the Fig. 5. In the picture, the area shown in the rectangular box was a small bulge and the right side bulge part corresponds to reflections of no. 4 ultrasonic sensor
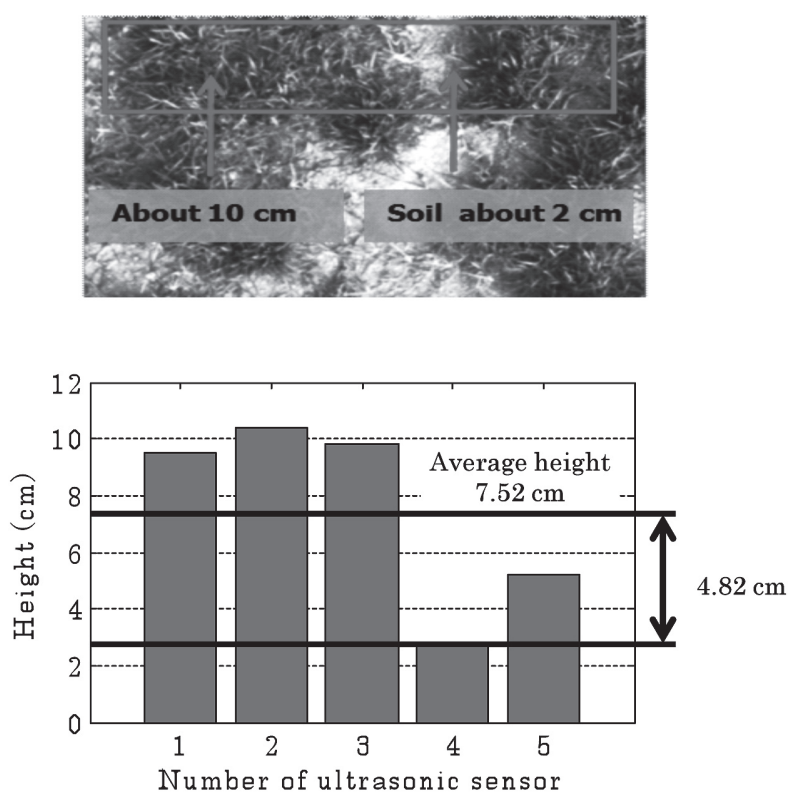

Fig. 5. Example of grass height determination using the ultrasonic module in the area of different growth levels. where grass height was lower than growth levels of the other parts.

The mean ultrasonic (MU) values could reflect the plant-to-senor distance from the ultrasonic sensors characteristics. In laboratory tests, the ultrasonic senor at a height of $100 \mathrm{~cm}$ to the ground was about $1.35 \mathrm{~V}$, and at $50 \mathrm{~cm}$, the sensor output was about $0.57 \mathrm{~V}$. The voltage and distance ratio was $0.0156 \mathrm{~V} / \mathrm{cm}$. The standard deviation (USD) of the ultrasonic output reflected the grass height difference of the same plane. In theory of inference, when the MU and USD are greater than 0.25 and 1.35 , respectively, the area would have less grass. With $R^{2}$ of 0.99 , the grass height was determined by converting the voltage signal $\mathrm{v}[0-5 \mathrm{~V}]$ into a distance $\mathrm{d}(\mathrm{cm}): \mathrm{d}$ $=16.744 \mathrm{~V}+50.481$.

\section{Crop circle estimation}

The crop circle ACS-430 sensor with 3 fixed wavebands covering red $(670 \mathrm{~nm})$, red-edge $(730 \mathrm{~nm})$, and near infrared $(780 \mathrm{~nm})$ region was used to collect the grass canopy reflectance $(R)$ on each measuring points. The spectral reflectance data was easily and quickly recorded to a text file on an SD flash card using the Holland Scientific GeoSCOUTGLS-400 data logger. The field of view of the crop circle ACS-430 sensor was an oval of $45^{\circ}$ range and the sensor readings were collected approximately $0.6 \sim 1 \mathrm{~m}$ above the grass canopy and at a constant speed along the data measuring line area.

$$
\mathrm{NDVI}=\frac{\mathrm{R}_{\mathrm{NIR}}-\mathrm{R}_{\mathrm{VIS}}}{\mathrm{R}_{\mathrm{NIR}}+\mathrm{R}_{\mathrm{VIS}}}
$$

\section{RESULTS AND DISCUSSION}

\section{Effects of sensor mounting}

\section{Effects of sensor height}

Height tests were conducted to find an optimal setting position of each sensor for grass growth estimation.

Height effect comparisons among the sensors are shown in Fig. 6. Difference was found from the mean sensor output values of the three fields. As an example for a $100 \mathrm{~cm}$ height, ultrasonic sensor voltage mean values were $1.273 \mathrm{~V}, 1.328 \mathrm{~V}$, and $1.372 \mathrm{~V}$, showing a trend of increase; bare soil rate mean values referred as CIS values were $2.76 \%, 14.34 \%$, and $16.86 \%$, showing a trend of increase for CCD camera; and NDVI mean values were 0.776, 0.656 and 0.429, showing a declining trend. During height change, ranges of standard deviation for the ultrasonic sensor were 0.003 0.005, 0.003 0.005, and $0.002 \sim 0.006$ for field 1 , and 3, respectively. It showed that the ultrasonic sensor accepted more interference due to the height increase, whereas, the CIS values and NDVI were not changed considerably. According to the crop circle user's manual, the optimal sensor-to-plant canopy distance should be between $55 \mathrm{~cm}$ to $152 \mathrm{~cm}$. Therefore, the height change had a little effect on the detection results for the crop circle sensor. 

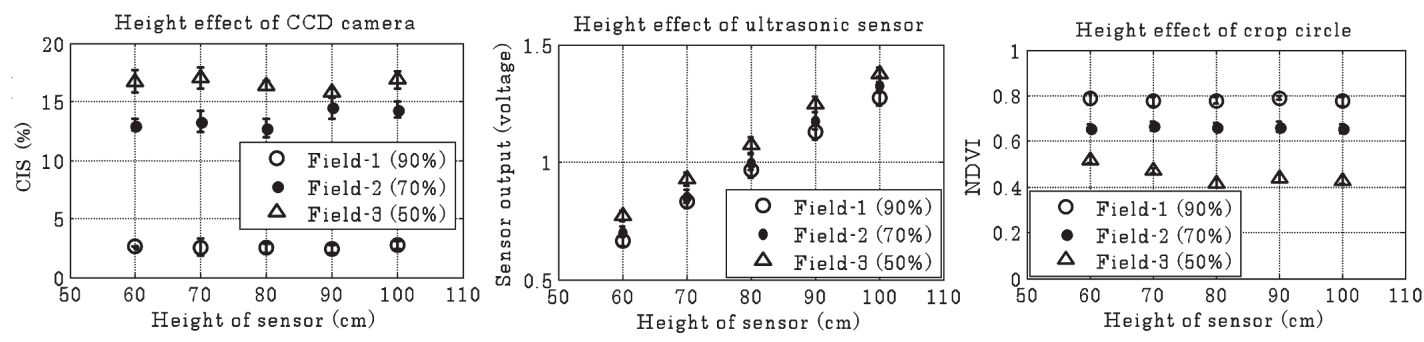

Fig. 6. Effects of sensor height.

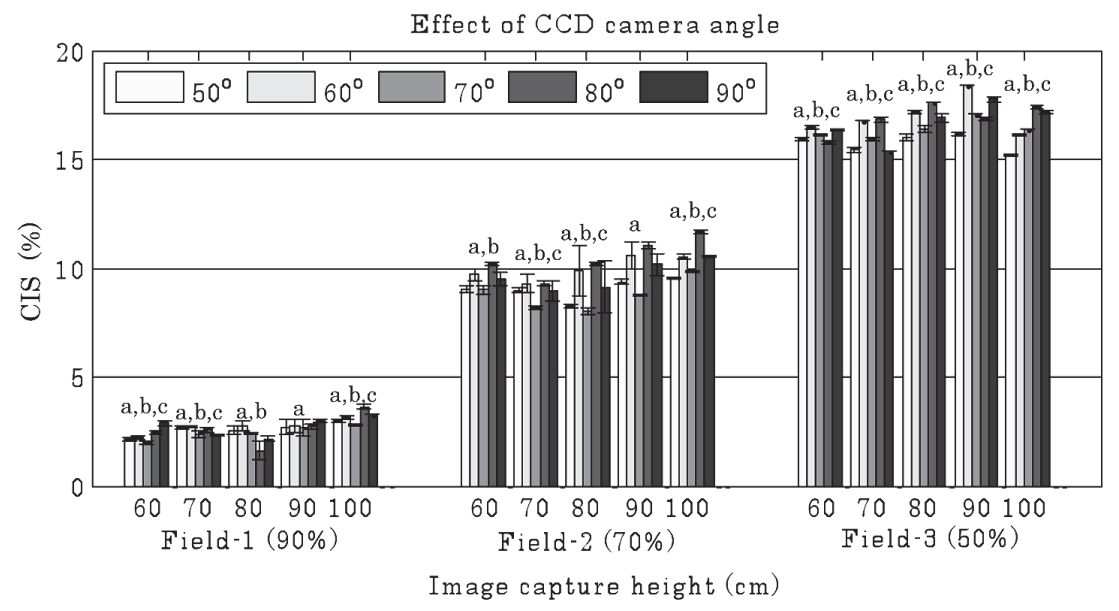

Fig. 7. Effects of CCD camera angle for different growth level fields and mounting heights.

\section{Effects of camera angle}

Camera capture angle would affect the image details such as brightness and shape of the captured area. Five capture angles were tested in the grass field with $90,80^{\circ}$, $70^{\circ}, 60^{\circ}$, and $50^{\circ}$ at different heights. Image processing results found by changing capture angles in three fields were shown in the Fig. 7. Standard ANOVA tests were conducted among different angles for the same height condition. Different letters were flanked on the above of each bar, indicating that the values with the same letters were not significantly different at a 5\% significance level. The CIS values indicating the percentage of bare soil rate were significantly different among the different fields. The CIS value due to the height change at a $90^{\circ}$ camera angle was proportional to grass growth level. The optimal case was found for $90^{\circ}$ angle compared to the $80^{\circ}$, $70^{\circ}, 60^{\circ}$ and $50^{\circ}$ camera capture angles. The captured images showed considerable noise at different viewpoints under the influence of light and shadow, whereas, the noise was relatively lower and had most simple status for image processing in case of $90^{\circ}$ capture angle.

\section{Effects of operation condition: static, vibration, and traveling}

The original image and processed image of CCD camera during static and vibration conditions are shown in Fig. 8. Histograms of the original gray images showed that two pictures mean gray value just had 3.6 differences, but the static status histogram was more fluency, indicating that the image was clearer. The image processing results showed $67.5 \%$ and $65.2 \%$ grass growth levels.

The collected 60 samples from the three different fields for each of the sensors were divided into 10 groups for manual grass growth level (40\% to 100\%) estimation
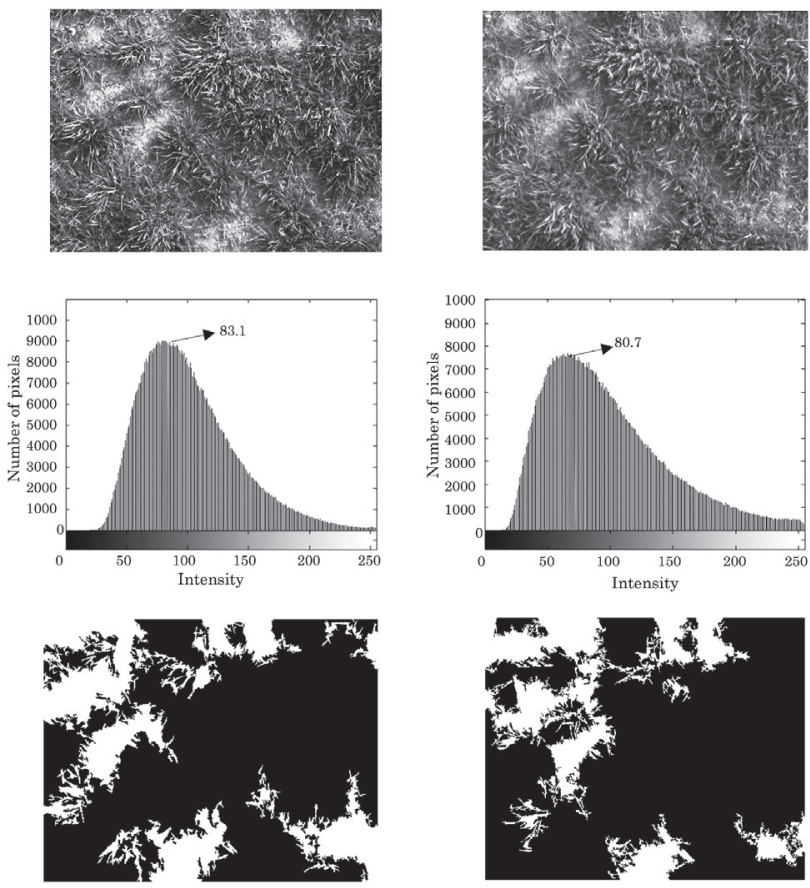

Fig. 8. Examples of image processing results under static (left) and vibration (right) status. 
and compared with NDVI data (0.52 to 0.78). The manual grass growth level had the same trend with NDVI data. This manual growth level was used to compare the grass growth levels obtained from the CCD camera images and grass heights from the ultrasonic sensors (Fig. 9).

The CIS values were obtained through image processing of 60 images from field 1, field 2, and field 3 at static condition to reflect the grass coverage. The CIS values were plotted against the 10 manually-determined grass growth levels. A linear regression equation was found for static condition with $R^{2}$ value of 0.143. Grass heights were measured from the 60 samples of ultrasonic sensor from three fields at static condition. These grass heights were plotted against the manual growth levels and a linear regression equation was obtained with $R^{2}$ of 0.097 . Similarly, 60 NDVI values were plotted against manual growth level and a linear regression equation with $R^{2}$ of 0.914 was found. Significance of the slopes of the regression lines for each sensor was tested by t-test and no significance differences were found at a $5 \%$ significance level.

CIS values, grass heights, and NDVI values of CCD camera, ultrasonic sensor, and crop circle were obtained from three different fields to reflect the grass coverage
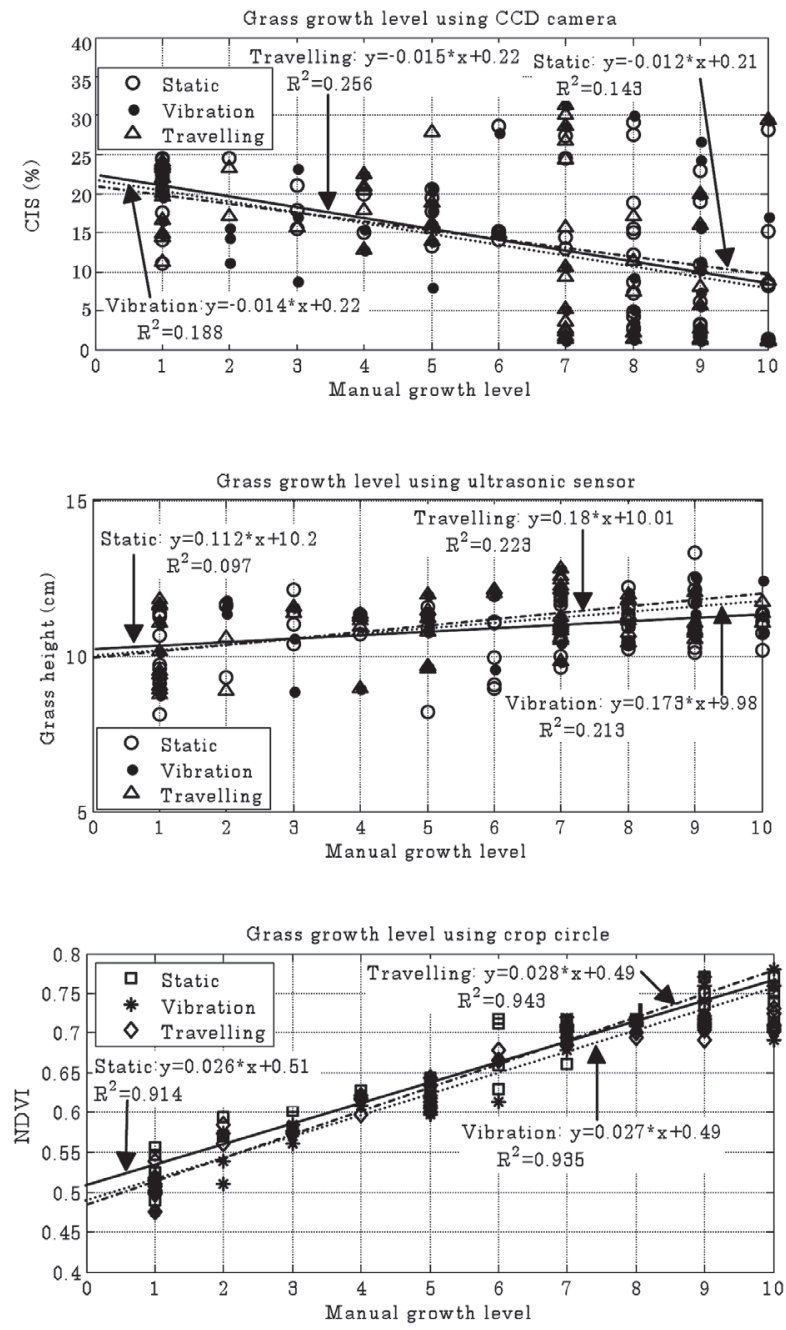

Fig. 9. Sensor comparison under static, vibration, and travelling with vibration conditions. at vehicle vibration and no traveling condition. Each sensor output values were plotted against the 10 manual grass growth levels. Linear regression equations with $R^{2}$ values of $0.188,0.213$, and 0.935 were obtained for CCD camera, ultrasonic sensor, and crop circle, respectively. Significance of the slopes of the regression lines for each sensor was tested by t-test and no significance differences were found at a 5\% significance level.

Similarly, CIS values, grass heights, and NDVI values of CCD camera, ultrasonic sensor, and crop circle were obtained from three different fields to reflect the grass coverage at vehicle vibration and traveling condition. CIS, grass heights, and NDVI values were plotted against the 10 manual grass growth levels and linear regression equations with $R^{2}$ values of $0.256,0.223$, and 0.943 were obtained for CCD camera, ultrasonic sensor, and crop circle, respectively. Significance of the slopes of the regression lines for each sensor was tested by t-test and no significance differences were found at a 5\% significance level.

Based on the test results under different operating conditions, it was concluded that the ultrasonic sensor could work with less deviation in the operating condition on static condition but followed worse grass growth status for vibration and travelling conditions. Crop circle proved its stability in the traveling work. The CCD camera showed better performances in all operating conditions.

\section{CONCLUSIONS}

This study was a basic research to evaluate different sensors for efficient and effective quantification of grass growth. Experiments from three different fields confirmed that the feasibility of grass detection could be done smoothly in all operating conditions using CCD camera. Static measurements confirmed the potential of this system to detect grass growth level. Especially the image processing could be implemented with a real-time vision detection system to estimate grass growth under dynamic condition. In the near future, the real-time vision detection system would be used in grass mapping test in fields and improvement of the system would be done to realize the fully automatic variable fertilizer application.

\section{ACKNOWLEDGEMENTS}

This research was supported by Technology Development Program for Agriculture and Forestry, Institute of Planning and Evaluation for Technology in Food, Agriculture, Forestry and Fisheries, Ministry of Agriculture, Food and Rural Affairs, Republic of Korea.

\section{REFERENCES}

Andújar, D., A. Escola', J. Dorado and C. Ferna'ndez-Quintanilla 2011 Weed discrimination using ultrasonic sensors. Weed Res., 51: 543-547

Andújar, D., M. Weis and R. Gerhards 2012 An ultrasonic system for weed detection in cereal crops. Sensors, 12: 17343-17357 
Aparicio, N., D. Villegas, J. Casadesus, J. L. Araus and C. Royo 2000 Spectral vegetation indices as non-destructive tools for determining durum wheat yield. Agron. J., 92: 83-91

Best, R. G. and J. C. Harlan 1985 Spectral estimation of green leaf area index of oats. Remote Sens. Environ., 17: 27-36

Cheng, H. D., X. H. Jiang, Y. Sun and J. Wang 2001 Color image segmentation: advances and prospects. Pattern Recogn., 34: 2259-2281

Choi, J. S. and G. M. Yang 2006 Sod production in South Korea. Asian J. Turfgrass Sci., 20: 237-251

Choi, J. M., W. Kim and T. H. Kang 2015 Acquisition of grass harvesting characteristics information and improvement of the accuracy of topographical surveys for the GIS by sensor fusion (I) - Analysis of grass harvesting characteristics by sensor fusion. J. of Biosystems Eng., $\mathbf{4 0}(1)$ : 28-34

Christensen, S. and J. Goudriaan 1993 Deriving light interception and biomass from spectral reflectance ratio. Remote Sens. Environ., 43: 87-95

Escolà, A., S. Planas, J. R. Rosell, J. Pomar, F. Camp, F. Solanelles, F. Gracia, J. Llorens and E. Gil 2011 Performance of an ultrasonic ranging sensor in apple tree canopies. Sensors, 11: 2459-2477

Freeman, K., W. K. Girma, D. B. Arnall, R. W. Mullen, K. L. Martin, R. K. Teal and W. R. Raun 2007 By-plant prediction of corn forage biomass and nitrogen uptake at various growth stages using remote sensing and plant height. Agron. J., 99: 530-536

Gée, C. H., J. Bossu, G. Jones and F. Truchetet 2008 Crop/weed discrimination in perspective agronomic images. Comput. Electron. Agric., 60: 49-59

Han, X. Z., H. J. Kim, H. C. Moon, H. J. Woo, J. H. Kim and Y. J. Kim 2013 Development of a path generation and tracking algorithm for a Korean auto-guidance tillage tractor. J. of Biosystems Eng., 38(1): 1-8

Haydu, J. J., A. W. Hodges and C. R. Hall 2006 Economic Impacts of the Turfgrass and Lawncare Industry in the United States. Publication \#FE632, Food and Resource Economics Department, Florida Cooperative Extension Service, Institute of Food and Agricultural Sciences, University of Florida, Gainesville, FL. Available at http://edis.ifas.ufl.edu/pdffiles/FE/ FE63200.pdf

Henik, J. J. 2012 Utilizing NDVI and Remote Sensing Data to Identify Spatial Variability in Plant Stress as Influenced by Management. M.Sc. thesis, Iowa State University, Ames, Iowa (USA) p. 48

Jang, D. H., N. I. Park, S. W. Yang and G. Y. Sim 2011 Present sit- uation of Zoysiagrass (Zoysia spp.) culture, sod production, and bland by prefecture in Japan. Asian J. Turfgrass Sci., 25(2): 229-236

Korea Forest Service 2012 Production Survey of Forest Products in 2011. Korea Forest Service, Daejeon (Korea) p. 588

Kraft, J. 2011 A flexible design framework for autonomous mowing. M.Sc. thesis, Massachusetts Institute of Technology, Cambridge, MA, p. 98

Lukina, E. V., M. L. Stone and W. R. Raun 1999 Estimating vegetation coverage in wheat using digital images. J. Plant Nutr., 22: $341-350$

Putti, F. F., C. P. Cremasco, L. R. A. G. Filho, A. R. do Reis 2014 Fertirrigation for vegetables grown in greenhouses. $J$. of Biosystems Eng., 39(4): 400-404

RDA 2013 Modularization of Korea's Development Experience: Policy for Promotion of Agricultural Mechanization and Technology Development. Northern Agriculture Research Institute, INC, Rural Development Administration (RDA) (Korea)

Shaver, T. M., R. Khosla and D. G. Westfal 2010 Evaluation of two ground-based active crop canopy sensors in corn: growth stage, row spacing, and sensor movement speed. Soil Sci. Soc. Am. J., 74: 2101-2108

Shaver, T. M., R. Khosla and D. G. Westfall 2011 Evaluation of two crop canopy sensors for nitrogen variability determination in irrigated maize. Precision Agric., 12: 892-904

Shibayama, M., T. Akiyama and K. Munakata 1985 A portable field ultrasonic sensor for crop canopy characterization. Remote Sens. Environ., 18(3): 269-279

Song, M. Z., M. S. N. Kabir, S. O. Chung, Y. J. Kim, J. K. Ha and K. H. Lee 2015 Path planning for autonomous lawn mower tractor. CNU J. Agric. Sci., 42(1): 63-71

White, R. W., J. L. Adrian and R. Dickens 1991 Alabama's Turfgrass-sod Industry. Alabama Agricultural Experiment Station, Bulletin 610, Auburn University (USA)

Woebbecke, D. M., G. E. Meyer, K. V. Bargen and D. A. Mortensen 1995 Color indices for weed identification under various soil, residue, and lighting conditions. Trans. ASAE, 38(1): 271-281

Youn, J. H., J. P. Lee and D. H. Kim 2005 The present situation of patented technology on turfgrass cultivar in domestic and foreign. Asian J. Turfgrass Sci., 19(2): 141-149

Youn, J. H., J. P. Lee and D. H. Kim 2006 Commercialization of patented technology on turfgrass production in Korea. Asian J. Turfgrass Sci., 20(1): 107-118 